\title{
Complexation of $\mathrm{Cm}$ (III) and $\mathrm{Eu}$ (III) with aqueous phosphates at elevated temperatures
}

\author{
NORBERT JORDAN ${ }^{1}$, NINA HUITTINEN ${ }^{2}$, ISABELLE \\ JESSAT $^{3}$, FLORENT RÉAL ${ }^{4}$, VALÉRIE VALLET ${ }^{4}$, \\ SEBASTIAN STARKE ${ }^{5}$ AND MANUEL EIBL ${ }^{6}$ \\ ${ }^{1}$ Helmholtz-Zentrum Dresden-Rossendorf e.V. VAT No. DE 140 \\ 213784 \\ ${ }^{2}$ Helmholtz-Zentrum Dresden Rossendorf \\ ${ }^{3}$ Helmholtz-Zentrum Dresden-Rossendorf \\ ${ }^{4}$ Université de Lille, CNRS, UMR 8523 - PhLAM - Physique \\ des Lasers Atomes et Molécules \\ ${ }^{5}$ Helmholtz-Zentrum Dresden - Rossendorf, Computational \\ Science Group (FWCC), Department of Information Services \\ and Computing (FWC) \\ ${ }^{6}$ Helmholtz-Zentrum Dresden-Rossendorf, Institute of Resource \\ Ecology \\ Presenting Author: n.jordan@hzdr.de
}

Thermodynamic databases are essential for the safety assessments of radioactive waste repositories. They have to be reliable, comprehensive, and describe the key mechanisms controlling the mobility of contaminants in the environment. However, in many cases these prerequisites are not fulfilled. An important example is the complexation of actinides and lanthanides with aqueous phosphates, for which this work provides complexation constants for spectroscopically identified species at $298 \mathrm{~K}$ and at elevated temperature.

The complexation of $\mathrm{Cm}(\mathrm{III})$ and $\mathrm{Eu}(\mathrm{III})$ was studied at submicromolar concentrations by laser-induced luminescence spectroscopy as a function of total phosphate concentration (0-

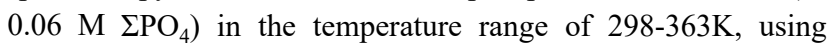
$\mathrm{NaClO}_{4}$ as a background electrolyte at $-\log \left[\mathrm{H}^{+}\right]$ranging from 2.5 to 3.6. The formation of both $\mathrm{CmH}_{2} \mathrm{PO}_{4}{ }^{2+} / \mathrm{EuH}_{2} \mathrm{PO}_{4}{ }^{2+}$ and $\mathrm{Cm}\left(\mathrm{H}_{2} \mathrm{PO}_{4}\right)_{2}{ }^{+} / \mathrm{Eu}\left(\mathrm{H}_{2} \mathrm{PO}_{4}\right)_{2}{ }^{+}$complexes was revealed, the latter being spectroscopically evidenced for the first time. Complexation constants were found to increase when raising the ionic strength from 0.5 to $3.0 \mathrm{M}$.

Temperature-dependent complexation constants for the identified species were derived and recalculated to standard conditions using the van't Hoff equation and the Specific Ion Interaction Theory. Endothermic and entropy driven reactions were established for both $\mathrm{Cm}(\mathrm{III})$ and $\mathrm{Eu}(\mathrm{III})$ phosphate complexes.

In addition, relativistic quantum chemical investigations were performed to study the complexation strength of $\mathrm{Cm}$ (III) with aqueous phosphates, to provide insight into potential changes of the coordination number with increasing temperature and to probe the character of the $\mathrm{Cm}$ water and $\mathrm{Cm}$ phosphate bonds. 